\title{
Index of tables
}

Table 1.1 Examples of some multi-lingual patent publishing authorities -15

Table 1.2 Key WIPO standards for bibliographic control of patents - 21

Table 1.3 WIPO standard codes for regional patent authorities and intergovernmental organisations -22

Table 1.4 Some important INID codes from ST.9 23

Table 2.1 Members and Extension States of the European Patent Organisation - $\mathbf{3 6}$

Table 2.2 Translation requirements of European Patents after the London

$$
\text { Agreement }-45
$$

Table 2.3 European Patent publication stages $-\mathbf{4 8}$

Table 2.4 Summary of current (2019) EPO document codes - 48

Table 2.5 European Patent databases - $\mathbf{5 1}$

Table 3.1 Publication milestones in US patent history - 60

Table 3.2 US application number series codes - 64

Table 3.3 US publication sequence -66

Table 3.4 US Re-issue publications -71

Table 3.5 Summary of historical and current US KD codes -72

Table 3.6 Redundant US KD codes -74

Table 3.7 United States patent databases -77

Table 4.1 Japanese Imperial Era and Western calendar dates - $\mathbf{8 2}$

Table 4.2 Japanese patent publication stages and number formats $-\mathbf{8 5}$

Table 4.3 Example of publication order under Japanese accelerated examination -87

Table 4.4 Database numbering conventions for publication of PCT national phase entry documents in Japan $-\mathbf{9 0}$

Table 4.5 Japanese utility model publication stages and number formats $-\mathbf{9 2}$

Table 4.6 Additional KD codes for Japan - 95

Table 4.7 Selected Japanese patent databases with English content - 96

Table 4.8 Selected Japanese-only patent sources - 97

Table 4.9 Subject coverage of PAJ -98

Table 5.1 Adoption date of publication languages under the PCT 102

Table 5.2 Changes in PCT numeration -106

Table 5.3 Operational status of the PCT International Search Authorities 108

Table 5.4 PCT KD codes 109

Table 5.5 PCT databases -117

Table 6.1 Canadian patent databases -126

Table 6.2 Formatting of French patent application numbers pre-1968 131

Table 6.3 KD codes in France prior to 1968 and transitional period to $1975-132$

Table 6.4 French KD codes for post-1968 patent applications - 133

Table 6.5 French patent databases 136

Table 6.6 German Intellectual Property Right numbering codes — 140

Table 6.7 German KD codes and sequences for national patent granting procedure -142

Table 6.8 German KD codes relating to EPO, PCT, translation and corrections (2004 onwards) -142 
Table 6.9 German patent databases -144

Table 6.10 Italian KD codes - 151

Table 6.11 Italian numbering systems for patents and utility models -153

Table 6.12 Italian patent databases -157

Table 6.13 Russian Federation application and publication number formats -162

Table 6.14 Russian Federation KD codes -165

Table 6.15 Russian patent databases -167

Table 6.16 EAPO application number formats - 171

Table 6.17 EAPO KD codes -171

Table 6.18 Extended GB publication sequence - $\mathbf{1 8 0}$

Table 6.19 United Kingdom KD codes (current) $-\mathbf{1 8 0}$

Table 6.20 Application process for Supplementary Protection Certificate in the UK - 181

Table 6.21 United Kingdom patent databases - 182

Table 7.1 Chinese numbering series 1985-date (patents) 189

Table 7.2 Examples of Chinese patent numbering in use -190

Table 7.3 Chinese numbering systems 1985-date (utility models) -191

Table 7.4 Examples of Chinese utility model numbering in use $\mathbf{1 9 2}$

Table 7.5 Chinese-language abbreviations for document types - 193

Table 7.6 Chinese patent databases 198

Table 7.7 Application and publication number formats for Hong Kong -202

Table 7.8 Indian application, publication and grant numbers (1972-2015) - 210

Table 7.9 Indian application, publication and grant numbers (2016-date) -213

Table 7.10 Indian patent databases — 215

Table 7.11 Variation in term of Korean patents and utility models -220

Table 7.12 South Korean numbering formats and KD codes (1948-1997) -221

Table 7.13 South Korean numbering formats and KD codes (1997-date) -223

Table 7.14 Korean patent databases - 226

Table 7.15 Application, publication and KD formats for DPR Korea -230

Table 7.16 Taiwan numbering systems -232

Table 7.17 Australian KD codes -240

Table 7.18 Australian patent application and publication numbering - 242

Table 7.19 Australian patent databases -245

Table 7.20 New Zealand KD codes (post 2017) - 249

Table 7.21 New Zealand application and publication numbering -250

Table 7.22 New Zealand patent databases -253

Table 8.1 Treaty and trading status of South American states (entry into force) -256

Table 8.2 Major patenting authorities in S. America, based on average grant rates 2013-2017 257

Table 8.3 Brazilian number formats 1971-date $-\mathbf{2 6 2}$

Table 8.4 KD codes used for Brazil (main series) -264

Table 8.5 KD codes used for Brazil (unofficial translation series) -265

Table 8.6 Brazilian patent databases $-\mathbf{2 6 6}$

Table 8.7 Application and publication number formats in Argentina -269

Table 8.8 KD codes used for Argentina -271

Table 8.9 Argentinian patent databases -271

Table 8.10 KD codes used for Chile -274 
Table 8.11 Chilean patent databases $-\mathbf{2 7 6}$

Table 8.12 Colombian numbering formats -279

Table 8.13 Application and publication sequences for Colombia - 281

Table 8.14 Colombian KD codes for published documents - 281

Table 8.15 Colombian patent databases $-\mathbf{2 8 2}$

Table 8.16 Application and publication number formats in Peru $-\mathbf{2 8 5}$

Table 8.17 KD codes for Peru - 286

Table 8.18 Peruvian patent databases $-\mathbf{2 8 6}$

Table 8.19 Decisions of the Andean Community in respect of patents $-\mathbf{2 8 9}$

Table 8.20 Mexican KD codes 295

Table 8.21 Mexican number formats and publication sequences for patents and utility models 297

Table 8.22 Mexican patent databases -299

Table $\mathbf{9 . 1}$ Treaty status of African states $-\mathbf{3 0 4}$

Table 9.2 Major patenting authorities in Africa, based on average grant rates 2011-2015- 310

Table 9.3 South African patent databases - $\mathbf{3 1 3}$

Table 9.4 Numbering schemes for Moroccan patent applications and grants -318

Table 9.5 Moroccan patent databases - 319

Table $\mathbf{9 . 6}$ Transition in Tunisia application numbering systems $-\mathbf{3 2 2}$

Table 9.7 Numbering schemes for Tunisian patent applications and grants 322

Table $\mathbf{9 . 8}$ Tunisian patent databases - $\mathbf{3 2 3}$

Table 9.9 Algerian publication and Bulletin dates -327

Table 9.10 Algerian patent databases - 328

Table 9.11 Numbering schemes for Egyptian patent applications and grants - 330

Table $\mathbf{9 . 1 2}$ Egyptian patent databases - 333

Table $\mathbf{9 . 1 3}$ Kenyan publication (grant) numbers by date -337

Table 9.14 Kenyan patent databases - 339

Table 9.15 Treaty and membership status of selected Middle East states — 341

Table 9.16 Major patenting authorities in the Middle East, based on average grant rates 2011-2015 342

Table 9.17 Patent rights scores for selected Middle East countries, compared to South Africa (after Park) $-\mathbf{3 4 2}$

Table $\mathbf{9 . 1 8}$ Israeli patent databases - $\mathbf{3 4 8}$

Table 9.19 Saudi application number formats -353

Table 9.20 Sequence of publications from Saudi Arabia - 354

Table 9.21 Saudi patent databases - 355

Table $\mathbf{9 . 2 2}$ Jordanian patent databases -358

Table $\mathbf{9 . 2 3}$ Iranian patent databases $-\mathbf{3 6 2}$

Table 11.1 Optical disk-based products produced under the EPO data standards -391

Table 11.2 A selection of non-EPO disk-based products - 393

Table 11.3 Derwent Chemical Patents Index (CPI) sections — 397

Table 11.4 Non chemical sections of DWPI -398

Table 11.5 Country coverage for selected multi-country databases $-\mathbf{4 0 2}$

Table 11.6 Example CPI and GMPI Manual Code hierarchies - 415

Table 11.7 Example Chemical fragmentation code hierarchy - $\mathbf{4 1 6}$

Table $\mathbf{1 1 . 8}$ Pharm country coverage $-\mathbf{4 2 4}$ 
Table 11.9 DEPATISnet full text coverage $-\mathbf{4 3 6}$

Table 11.10 Google Patents full text coverage (2020) -437

Table 11.11 PatentScope full text country coverage (national collections, excluding PCT) -440

Table 11.12 Total Patent One, PatBase and PatSeer full-text content $-\mathbf{4 4 2}$

Table 11.13 Principal country coverage of the WIPS Global service - 451

Table 12.1 Example hierarchies from The New Walford, Volume 1- 468

Table 12.2 Selected repositories and preprint servers -475

Table 12.3 Selected search engines for social media - 478

Table 13.1 The Derwent range of patent current awareness products (2018) -484

Table 13.2 Bentham Science "Recent Patents on . . ." journals - 486

Table 16.1 Selected Asian legal status registers - $\mathbf{5 1 8}$

Table 16.2 INPADOC PRS and PatentScope legal status coverage (2020) - $\mathbf{5 2 2}$

Table 16.3 Content of the Global Dossier system - $\mathbf{5 2 8}$

Table 17.1 Patent analysis, visualisation and Al-assisted search tools - $\mathbf{5 3 7}$

Table 18.1 IPC revision periods (1968-2005) $-\mathbf{5 4 3}$

Table 18.2 IPC reform and ongoing revisions - 544

Table 18.3 Variations in classification for members of the same patent family $\mathbf{Z} \mathbf{5 4 8}$

Table 19.1 WIPO patent information activities - $\mathbf{5 6 0}$ 